\title{
PERAN KELUARGA DALAM MENJAGA KESELAMATAN PASIEN RAWAT INAP DI RUMAH SAKIT
}

\author{
Dewi Meylinta Sembiring Dewimeylinta7@ gmail.com
}

\section{LATAR BELAKANG}

Hampir setiap tindakan medis menyimpan potensi resiko. Banyaknya jenis obat, jenis pemeriksaan dan prosedur, serta jumlah pasien dan staf rumah sakit yang cukup besar,merupakan hal yang potensial bagi terjadinya bahaya dan adverse events. Adverse Event atau Kejadian Tidak Diharapkan (KTD) merupakan suatu kejadian yang mengakibatkan cedera yang tidak diharapkan pada pasien karena suatu tindakan (commission) atau tidak mengambil tindakan yang seharusnya diambil (omission), dan bukan karena "underlying disease" atau kondisi pasien. Kesalahan tersebut bisa terjadi dalam tahap diagnostic seperti kesalahan atau keterlambatan diagnose, tidak menerapkan pemeriksaan yang sesuai, menggunakan cara pemeriksaan yang sudah tidak dipakai atau tidak bertindak atas hasil pemeriksaan atau observasi; tahap pengobatan seperti kesalahan pada prosedur pengobatan, pelaksanaan terapi, metode penggunaan obat, dan keterlambatan merespon hasil pemeriksaan asuhan yang tidak layak; tahap preventive seperti tidak memberikan terapi provilaktik serta monitor dan follow up yang tidak adekuat; atau pada hal teknis yang lain seperti kegagalan berkomunikasi, kegagalan alat atau system yang lain. Disinilah peran keluarga sebagai partner pelayanan kesehatan sangat penting untuk mencegah terjadinya bahaya atau adverse events.

Keluarga merupakan bagian dari tim pengobatan dan perawatan. Maka, peran keluarga penting untuk memantau kebutuhan pasien dari laporan perawat atau jika perlu malakukan komunikasi langsung. Keluarga merupakan sistem pendukung pertama dan utama bagi individu. Dukungan keluarga yang baik bisa menjadi sumber motivasi, semangat dan perlindungan terhadap resiko-resiko bahaya kepada pasien. Keluarga merupakan unit paling dekat dengan pasien, dan merupakan perawat utama bagi pasien. Keluarga berperan dalam menentukan cara atau perawatan yang diperlukan pasien di rumah sakit. Keberhasilan perawat di rumah sakit akan sia sia jika tidak dibantu dengan keluarga yang berperan sebagai partner pelayanan kesehatan. 
Peran serta keluarga sejak awal perawatan di rumah sakit akan berpengaruh terhadap keadaan pasien. Maka dari itu sangat diperlukan peran keluarga sebagai partner bagi pelayanan kesehatan.

\section{METODE}

Metode yang digunakan adalah metode kualitatif dan metode literature review, yaitu dengan mengumpulkan data, membaca, mengkaji dan menganalisis data tersebut dari berbagai sumber seperti buku teks, e-book,jurnal,buku referensi yang berhubungan dengan tema yaitu peran pasien dan keluarga sebagai partner di pelayanan kesehatan untuk mencegah terjadinya bahaya dan adverse events. Literature yang digunakan adalah sebanyak 12 dari berbagai sumber dengan ketentuan tahun terbit terakhir adalah tahun 2012 atau paling lama diterbitkan 8 tahun terakhir.

\section{HASIL}

Pasien yang dirawat di rumah sakit merupakan individu yang sedang memiliki masalah kesehatan, sehingga dimungkinkan mengalami kesulitan memenuhi kebutuhan pribadi termasuk menjaga keselamatan sendiri, oleh sebab itu pasien membutuhkan dukungan dari keluarga untuk menjaganya dan mencegah bahaya/cedera. Patient Safety atau keselamatan pasien adalah suatu system yang membuat asuhan pasien di rumah sakit menjadi lebih aman. Sistem ini mencegah terjadinya cedera yang disebabkan oleh kesalahan akibat melaksanakan suatu tindakan atau tidak mengambil tindakan yang seharusnya diambil. Tujuan "Patient safety" adalah 1.Terciptanya budaya keselamatan pasien di RS 2. Meningkatnya akuntabilitas rumah sakit thdp pasien dan masyarakat 3.Menurunnya KTD di RS 4.Terlaksananya program-program pencegahan sehingga tidak terjadi pengulangan KTD.

Salah satu Standar Keselamatan Pasien adalah mendidik pasien dan keluarga. Standarnya adalah RS harus mendidik pasien \& keluarganya tentang kewajiban \& tanggung jawab pasien dalam asuhan pasien, dengan kriteria Keselamatan dalam pemberian pelayanan dapat ditingkatkan dgn keterlibatan pasien adalah partner dalam proses pelayanan. Rumah Sakit dalam upaya memberikan pelayanan kesehatan melibatkan tim kerja dari berbagai profesi, maka rumah sakit menyiapkan sistem layanan terintegrasi yang berfokus pada pasien untuk memberi pelayanan yang aman dengan enam sasaran keselamatan pasien yaitu 1. Ketepatan identifikasi 
pasien 2. Komunikasi efektif 3. Pemberian obat secara aman 4. Ketepatan pasien, lokasi dan prosedur operasi 5. Pencegahan infeksi 6. Pencegahan pasien jatuh.

Peran keluarga sesuai dengan tugas-tugas keluarga dalam bidang kesehatan salah satunya adalah memberikan perawatan kepada anggota keluarga yang sakit dan yang tidak dapat membantu dirinya sendiri karena cacat atau usia terlalu muda. Peran keluarga tersebut meliputi mengingatkan/memonitor waktu minum obat, mengontrol persediaan obat, mengantarkan penderita kontrol, memisahkan alat-alat penderita dengan anggota keluarga lain, meningkatkan kesehatan lingkungan penderita, dan pemenuhan kebutuhan psikologis agar penderita tidak merasa terisolir dalam lingkungannya

Dalam melaksanakan program tersebut diperlukan kerja sama antara tim kesehatan serta pasien dan keluarga. Lalu bagaimana peran keluarga secara aktif dalam menjaga keselamatan pasien rawat inap? Dan bagaimana penerapan 6 sasaran keselamatan pasien dan peran keluarga dalam menjaga keselamatan pasien rawat inap di rumah sakit yang sebelumnya telah dipaparkan point-pointnya? Penjelasanya akan disampaikan pada bagian pembahasan.

\section{PEMBAHASAN}

Berdasarkan pencarian dari berbagai literature yang sesuai dengan judul dan pokok pembahasan yaitu peran keluarga dalam menjaga keselamatan pasien rawat inap di rumah sakit , berikut adalah pembahasan dari hasil yang didapat.

Untuk berfungsinya peran secara adequat merupakan hal yang sangat penting bukan hanya untuk berfungsinya individu secara sukses melainkan juga untuk keberhasilan fungsi keluarga. Fungsi-fungsi keluarga dicapai lewat penampilan peranperan keluarga (Marilyn. M. Friedman, 1998; 286). Menurut Dovali dan Logan (1986) keluarga adalah sekumpulan orang dengan ikatan perkawinan, kelahiran, dan adopsi yang bertujuan untuk menciptakan, mempertahan kan budaya dan meningkatkan perkembangan fisik, mental, emosional serta sosial dari setiap anggota keluarga. Dimana keluarga memiliki fungsi yang salah satunya adalah tugas kesehatan keluarga yang menurut Friedman (1988) yaitu keluarga mampu memberi perawatan pada anggota keluarga yang sakit, keluarga mampu mempertahankan/ menciptkan suasana rumah yang sehat dan keluarga mampu membuat keputusan tindakan kesehatan yang tepat. 
Pada bagian Hasil terdapat Salah satu Standar Keselamatan Pasien adalah mendidik pasien dan keluarga .Dalam melaksanakan program tersebut diperlukan kerja sama antara tim kesehatan serta pasien dan keluarga. Peran keluarga secara aktif dalam menjaga keselamatan pasien rawat inap adalah:

Memberikan informasi yang benar, jelas, lengkap dan jujur

$>$ Mengetahui dan melaksanakan kewajiban serta tanggung jawab pasien maupun keluarga.

$>$ Mengajukan pertanyaan-pertanyaan untuk hal yang tidak dimengerti.

$>$ Memahami dan menerima konsekuensi pelayanan.

$>$ Mematuhi dan menghormati peraturan rumah sakit.

$>$ Memperlihatkan sikap menghormati dan tenggang rasa dalam proses bersama tim kesehatan mengelola pasien

Memenuhi kewajiban finansial yang disepakati.

Penerapan enam sasaran keselamatan pasien dan peran keluarga dalam menjaga keselamatan pasien rawat inap di rumah sakit akan dijelaskan sebagai berikut :

\section{Ketepatan Identifikasi Pasien}

Pasien dalam keadaan tidak sadar, gelisah, mengalami gangguan penglihatan, gangguan pendengaran, gangguan proses pikir, mendapat obat bius, atau gangguan lain tidak mampu melakukan identifikasi diri dengan benar selain itu pasien yang pindah ruang rawat atau bertukar tempat tidur saat perawatan di rumah sakit berisiko mengalami ketidaktepatan identifikasi, maka rumah sakit menyusun sistem untuk memastikan identifikasi pasien sebagai individu yang akan menerima pelayanan adalah tepat dan jenis pelayanan atau pengobatan terhadap individu tersebut adalah sesuai.

Peran Pasien dan keluarga untuk memastikan ketepatan identifikasi pasien adalah:

- Memberikan data diri yang tepat pada saat mendaftar sesuai dokumen data diri yang dimiliki. Data utama yang diperlukan adalah nama dan tanggal lahir

- Selama rawat inap pasien dipakaikan gelang. Pasien dan keluarga harus memahami fungsi gelang dan patuh menggunakan gelang tersebut selama rawat inap karena gelang 
tersebut dipakai oleh tim kesehatan guna memastikan kebenaran identitas dan faktor risiko pasien saat memberikan pelayanan.

$\varnothing \quad$ Gelang warna biru untuk laki-laki dan gelang warna merah muda untuk perempuan dipakai untuk identifikasi

$\varnothing \quad$ Gelang warna merah dipasangkan pada pasien yang memiliki riwayat alergi

$\varnothing \quad$ Gelang warna kuning dipasangkan pada pasien yang memiliki risiko jatuh

- Pasien atau keluarga kooperatif saat dilakukan verifikasi identitas oleh petugas saat akan melakukan tindakan, memberikan obat, mengambil preparat untuk pemeriksaan laborat dan lain-lain.

\section{Komunikasi efektif}

Pasien yang menjalani rawat inap dikelola oleh dokter dan berbagai profesi lain sebagai tim dengan menerapkan sistem komunikasi yang efektif untuk memberikan pelayanan

Peran pasien dan keluarga mewujudkan komunikasi efektif adalah:

- Menunjuk atau menetapkan anggota keluarga yang diberi kewenangan untuk berkomunikasi dengan tim kesehatan. Penunjukkan ini diperlukan untuk memastikan komunikasi berlangsung efektif dan berkesinambungan, tidak mengalami rantai komunikasi yang panjang dan kompleks yang berisiko menyebabkan perubahan makna isi informasi.

- Memberikan informasi dan data terkait kondisi pasien kepada tim kesehatan dengan benar dan jelas.

- Memberikan informasi pada petugas bila ada kejadian tidak diharapkan.

- Meminta informasi yang diperlukan kepada tim kesehatan

\section{Pemberian obat secara aman}

Pemberian obat merupakan bagian yang mengambil porsi dominan dalam tata kelola pasien rawat inap.

Peran serta keluarga dalam menjamin keamanan pemberian obat adalah 
- Memberikan informasi yang lengkap tentang riwayat obat yang pernah dipergunakan sebelum masuk rumah sakit

- Memberikan informasi tentang riwayat alergi atau reaksi yang dialami saat menggunakan obat tertentu

- Mendukung pengawasan pemberian obat selama rawat inap dengan cara memastikan identitas pasien benar, menanyakan jenis obat yang diberikan, tujuan pemberian, dosis dan waktu pemberian obat

\section{Kepastian Tepat-Lokasi, Tepat-Prosedur, Tepat-Pasien Operasi}

Tindakan operasi merupakan salah satu prosedur yang mungkin dilakukan pada pasien untuk mengatasi masalah kesehatannya. Bagian tubuh yang akan dioperasi bisa meliputi bagian yang bersisi (misalnya tangan atau kaki kanan dan kiri, mata kanan dan kiri) atau bagian yang multipel level (misalnya tulang belakang) atau bagian yang multipel struktur (misalnya jari tangan) dengan demikian diterapkan sistem untuk memastikan tindakan tepat-lokasi, tepat-prosedur, tepat-pasien. Salah satu prosedur yang dilakukan sebelum tindakan operasi adalah proses verifikasi. Peran pasien dan keluarga dalam proses verifikasi praoperasi adalah memberikan informasi yang benar dan bekerja sama secara kooperatif Proses yang dilakukan meliputi :

- Verifikasi lokasi, prosedur, dan pasien yang benar. Proses ini dilakukan dengan membuat tanda pada lokasi yang dioperasi. Penandaan lokasi operasi ini melibatkan pasien, dibuat oleh dokter yang akan melakukan tindakan dan dilaksanakan saat pasien dalam keadaan sadar .Tanda ini tidak boleh dihapus dan harus terlihat sampai saat akan disayat.

- Memastikan bahwa semua dokumen, foto (imaging), hasil pemeriksaan yang relevan tersedia, diberi label dengan baik

- Melakukan verifikasi ketersediaan peralatan khusus yang dibutuhkan.

\section{Pengurangan risiko infeksi terkait pelayanan kesehatan}

Rumah sakit merupakan tempat yang memungkinkan berkumpulnya berbagai jenis kuman sedangkan pasien yang sedang dirawat memiliki daya tahan tubuh relatif rendah dengan demikian diperlukan suatu proses bersama untuk mencegah timbulnya infeksi lain yang tidak berhubungan dengan penyakit utama pasien 
Peran pasien dan keluarga dalam pengurangan risiko terkait pelayanan kesehatan adalah :

- Menerapkan prosedur cuci tangan yang benar

Keluarga memiliki kemungkinan sering kontak dengan pasien, maka untuk melindungi diri sendiri dan melindungi pasien dari perpindahan kuman disarankan keluarga menerapkan prosedur cuci tangan yang benar pada 5 (lima) momen yaitu saat sebelum kontak dengan pasien, sesudah kontak pasien, sesudah ke toilet, sebelum dan sesudah makan. Perlu diperhatikan juga bahwa lingkungan sekitar pasien berisiko terpapar kuman maka disarankan mencuci tangan sesudah kontak dengan lingkungan pasien (meja, alat tenun, tempat tidur dsb), Guna memperoleh hasil cuci tangan yang optimal Pasien dan keluarga disarankan mencermati dan mengikuti petunjuk 6 (enam) langkah mencuci tangan yang diberikan oleh petugas atau panduan cuci tangan yang ada di rumahsakit

- Membatasi pengunjung pasien

Selama pasien dirawat di rumah sakit seyogyanya pasien tidak berinteraksi dengan banyak orang karena berisiko terpapar kuman dari pengunjung dalam keadaan pertahanan diri yang relatif rendah dengan demikian peran keluarga diperlukan untuk membatasi pengunjung yang kontak dengan pasien

- Menerapkan etika batuk yang benar

Keluarga dan pengunjung yang batuk berisiko menyebarkan kuman melalui partikel halus di udara dengan demikian bila sedang mengalami batuk keluarga perlu menggunakan masker atau menerapkan tehnik perlindungan yang benar saat batuk yaitu menutup mulut dan hidung menggunakan lengan.

\section{Pengurangan Risiko Pasien Jatuh}

Individu yang sedang sakit memiliki keterbatasan dalam pengamanan diri termasuk menghindari jatuh. Rumah sakit mengambil tindakan untuk mengurangi risiko dengan melakukan pengkajian faktor-faktor yang dapat menyebabkan jatuh seperti, penggunaan obat, gaya jalan dan keseimbangan, alat bantu berjalan yang digunakan oleh pasien, riwayat jatuh saat berjalan atau saat istirahat baring di tempat tidur. 
Peran pasien dan keluarga dalam mencegah jatuh saat dirawat di rumah sakit adalah :

- Pastikan penanda pasien beresiko jatuh berupa gelang kuning dipakai pasien

- Jangan melepas atau memindah kartu kuning yang dipasang petugas dekat tempat tidur pasien atau di depan kamar pasien karena kartu tersebut merupakan penanda untuk mewaspadai pasien yang beresiko jatuh

- Keluarga atau pasien perlu memastikan diri untuk memahami informasi yang diberikan oleh petugas agar dapat mendukung tindakan pencegahan jatuh.

Informasi yang perlu diketahui adalah:

- faktor resiko jatuh yang teridentifikasi seperti obat yang dipergunakan, kesadaran pasien, keseimbangan saat berjalan, dll

- tindakan pencegahan jatuh yang perlu dilakukan

- cara untuk minta bantuan

- cara menggunakan bel atau sarana komunikasi di ruangan

- cara mengatur pengamanan tempat tidur

- pengggunaan tali pengaman, dll

\section{PENUTUP}

Kesimpulan

Pengelolaan pasien rawat inap tidak hanya mejadi tanggung jawab tim kesehatan tetapi melibatkan juga pribadi pasien sendiri dan keluarga, maka setiap bagian perlu menjalankan peran masing-masing sesuai tugasnya. Terutama keluarga, yang berperan aktif dalam menjaga keselamatan pasien dari berbagai bahaya karena hampir setiap tindakan medis menyimpan potensi resiko. Banyaknya jenis obat, jenis pemeriksaan dan prosedur, serta jumlah pasien dan staf rumah sakit yang cukup besar,merupakan hal yang potensial bagi terjadinya bahaya dan adverse events Disinilah peran keluarga sebagai partner pelayanan kesehatan sangat penting untuk mencegah terjadinya bahaya atau adverse events.

Keluarga merupakan bagian dari tim pengobatan dan perawatan. Maka, peran keluarga penting untuk memantau kebutuhan pasien. Keberhasilan perawat di rumah sakit akan sia sia jika tidak dibantu dengan keluarga yang berperan sebagai partner pelayanan kesehatan. Karena proses kerja sama yang baik merupakan dasar yang kuat untuk memperoleh hasil yang optimal. 


\section{DAFTAR PUSTAKA}

Abubakar Nabillah, Neffrety Nilamsari. (2017). Pengetahuan dan Sikap Keluarga Pasien Rawat Inap Rumah Sakit Haji Surabaya . Jurnal manajemen kesehatan universitas Airlangga 3(1), 4961.

Fitrawati, Pabuty, Putra. (2012). Pelaksanaan Program Keselamatan Pasien di RSUD Solok. Jurnal Kesehatan Masyarakat 6(2), 73-79.

Fitriana Yuni, Kurniasari Pratiwi. (2018). Pelaksanaan Patient Safety Di Rumah Sakit Umum Daerah Dan Rumah Sakit Umum Swasta Bantul Berdasarkan Ketentuan Undang-Undang nomor 44 Tahun 2009 Tentang Rumah Sakit. Jurnal akademi kebidanan Yogyakarta, 7(1),28-39.

Iskandar Edy. (2017). Tata Kelola dan Kepatuhan Penerapan Standar Patient Safety Penyakit Stroke di Rumah Sakit Dr.Kanujoso Djatiwibowo Tahun 2015. Jurnal ARSI fakultas kesehatan masyarajat universitas Indonesia 3(3), 169-180.

Juniarti Nanda Hani, Ahmad Agid Mudayana (2018).Penerapan Standar Keselamatan Pasien Di

Rumah Sakit Umum Daerah Provinsi Nusa Tenggara Barat. Jurnal kesehatan poltekes Ternate, 11(2),93-108.

Priyoto, Widyastuti.(2014). Kebutuhan Dasar Keselamatan Pasien. Jogjakarta: Graha Ilmu.

Pujilestari, Maidin, Anggraeni. (2013).Gambaran Budaya Keselamatan Pasien Oleh Perawat Dalam Melaksanakan Pelayanan di Instalasi Rawat Inap RSUP dr.Wahidin Sudirohusodo. Jurnal keperawatan,10(1),74-105.

Simamora, R.H. (2019). Buku ajar pelaksanaan identifikasi pasien. Uwais Inspirasi Indonesia.

Syam, Nur. (2017). Implementasi Budaya Keselamatan Pasien Oleh Perawat di Rumah Sakit Ibnu Sina Makasar. Jurnal fakultas kesehatan masyarajat universitas Indonesia 11(2), 169-174.

Tutiany, Lindawati, Paula Krisanti. (2017). Manajemen Keselamatan Pasien. Jakarta: Kementrian Kesehatan Republik Indonesia. 
Yusuf Muhammad. (2017). Penerapan Patient Safety Di Ruang Rawat Inap Rumah Sakit Umum Daerah Dr. Zainoel Abidin. Jurnal keperawatan universitas Syiah Kuala Banda Aceh, 5(1),8589. 